\title{
Adequação ao Real de Adolescentes: Possibilidades Informativas do Questionário Desiderativo ${ }^{1}$
}

\author{
Nicole Medeiros Guimarães ${ }^{2}$ \\ Vara da Infância e Juventude, São José do Rio Preto \\ Sonia Regina Pasian \\ Universidade de São Paulo, Ribeirão Preto
}

\begin{abstract}
RESUMO - O presente trabalho constitui-se em um recorte de uma investigação voltada para a busca de padrões de desempenho de adolescentes diante do Questionário Desiderativo. Responderam, individualmente, a essa técnica projetiva, 120 adolescentes, voluntários de ambos os sexos, sem história de transtornos no desenvolvimento, estudantes do Ensino Médio de escolas públicas e particulares de Ribeirão Preto (SP). Suas respostas ao Desiderativo foram avaliadas às cegas por três examinadores independentes. Neste trabalho foram destacados os indicadores técnicos do Desiderativo referentes à Adequação ao Real, a saber: Tempo de Reação Médio, Sequência das Escolhas, Necessidade de Indução, Respostas Antropomórficas e Respostas Vulgares (mais frequentes). Os resultados apontaram indícios de precisão, oferecendo bons subsídios para a utilização, cientificamente fundamentada, do Questionário Desiderativo por psicólogos brasileiros.
\end{abstract}

Palavras-chave: adolescência; adequação ao real; técnicas projetivas; questionário desiderativo.

\section{Adequacy to Reality of Adolescents: Informative Possibilities of the Desiderative Questionnaire}

\begin{abstract}
This paper is a sample of an investigation on the adolescents' performance patterns in the Desiderative Questionnaire. This questionnaire was individually applied to 120 voluntary adolescents of both genders, without history of developmental disturbances, attending public and private high schools in Ribeirão Preto (SP). Three independent examiners evaluated their answers in the Desiderative. For this work, only the Desiderative's technical indicators on Adequacy to Reality were selected, which were: Average Reaction Time, Choice Sequence, Necessity of Induction, Anthropomorphic Answers, and Common Answers (more frequent). The results indicated precision, offering solid basis, scientifically grounded, for the use of the Desiderative Questionnaire by Brazilian psychologists.
\end{abstract}

Keywords: adolescents; adequacy to reality; projective techniques; desiderative questionnaire.

Dentro da diversidade de instrumentos de avaliação psicológica, o Questionário Desiderativo tem se destacado, na prática clínica, como importante técnica projetiva, favorecedora de relevantes informações sobre os dinamismos da personalidade dos indivíduos (Brêga, Frazatto \& Loureiro, 2001; Ocampo, Arzeno \& Piccolo, 1979/1985; Paulo, 2005).

O Desiderativo fornece informações acerca do funcionamento psicodinâmico, como recursos defensivos, força do ego, aspectos afetivos, entre outras informações importantes em avaliação psicodiagnóstica de abordagem psicodinâmica (Nijamkin \& Braude, 1996/2000). É um instrumento aplicável a uma grande parcela da população, além de ter seu uso favorecido por economia de tempo e por não exigir habilidades específicas para respondê-lo. Essas características

1 Este trabalho é derivado de Projeto de Mestrado da primeira autora sob a orientação da segunda autora, com subvenção da CAPES. Agradecimento especial às psicólogas Érika Tiemi Kato Okino, Maria Luisa Casillo Jardim Maran e Mariana de Siqueira Bastos Formiguieri, pelo auxílio na análise dos dados.

2 Endereço para correspondência: Universidade de São Paulo. Faculdade de Filosofia, Ciências e Letras de Ribeirão Preto. Departamento de Psicologia e Educação. Av. Bandeirantes, 3900. Bairro Monte Alegre. Ribeirão Preto, SP. CEP 14040-901.E-mail: nmguimaraes@yahoo. com.brousrpasian@ffclrp.usp.br. destacam a técnica projetiva como um instrumento bastante promissor para o campo da avaliação psicológica.

Nijamkin e Braude (1996/2000) desenvolveram um sistema avaliativo detalhado para essa técnica projetiva. Por sua vez, Brêga, Frazatto e Loureiro (2000) elaboraram uma esquematização das principais funções psicológicas avaliadas pelo Desiderativo, com base na proposição de Nijamkin e Braude, e organizaram um protocolo de codificação das respostas colhidas por meio desse instrumento. Um exemplo de aplicação prática desse sistema avaliativo é o estudo, desenvolvido por essas mesmas autoras, sobre características de personalidade de pessoas com funcionamento paranóide (Brêga \& cols., 2001).

Dentro do rol de informações psicodinâmicas possíveis de serem obtidas por meio do Questionário Desiderativo, conforme a proposição avaliativa referida, os indicadores referentes à Adequação ao Real merecem especial atenção. Isso porque informam sobre a aparente e a global adaptação (ou não) do indivíduo a seu contexto (no caso, à tarefa desiderativa). Esses indicadores formais do Desiderativo referem-se, portanto, à representação projetiva da adequação do indivíduo às demandas da realidade, avaliando-se sua maior ou menor possibilidade de responder adequadamente às consignas do instrumento. 
Para avaliar esses recursos individuais são examinados quatro indicadores técnicos do Desiderativo, conforme Brêga e cols. (2000), a saber:

a) Tempo de reação médio (TRM). Corresponde à média aritmética (em segundos) dos períodos de latência para cada consigna que, por sua vez, são os tempos decorridos desde a proposição da pergunta até o momento da verbalização de cada resposta. O TRM informa sobre o ritmo interno de trabalho psíquico, indicando o tempo despendido pelo indivíduo para manejar a ansiedade provocada pelas consignas e para realizar suas escolhas projetivas.

b) Sequência das escolhas. Nesse tópico são avaliados diferentes quesitos, a saber: (1) quantas respostas foram necessárias para completar a tarefa; (2) a quais reinos se referem as respostas fornecidas pelos examinandos (animal, vegetal ou inanimado); e (3) em qual ordem esses reinos apareceram nas respostas. Em uma pessoa com funcionamento psíquico saudável (Ocampo \& cols., 1979/1985), existiria a sobreposição dos instintos de conservação sobre os de morte, o que se verificaria pela emissão, em primeiro lugar, de respostas com maior carga de vitalidade (reino animal), depois o reino vegetal e, por último, as respostas nas quais a desvitalização é marca predominante (reino inanimado).

c) Necessidade de indução. Dentro desse indicador são considerados os seguintes aspectos: (1) necessidade (ou não) de indução da resposta; (2) qual reino foi induzido; e (3) qual a razão da necessidade dessa intervenção do aplicador, ou seja, qual foi a falha ocorrida ao responder. A presença de necessidade de indução está relacionada a dificuldades do indivíduo em seguir adequadamente as instruções do teste, e, projetivamente, a problemas nas funções psicológicas relacionadas à adequação ao real (Nijamkin \& Braude, 1996/2000).

d) Respostas antropomórficas. São as escolhas de elementos para-humanos, ou seja, elementos onde permanece presente a identidade humana. Dessa forma, funcionam como indicadores de dificuldades em dissociar-se da identidade humana, ocorrendo falha ao responder (Nijamkin \& Braude, 1996/2000). Esse processo, por sua vez, fornece indícios de elevado impacto das instruções do Desiderativo sobre a dinâmica psíquica do indivíduo, a ponto de não conseguir responder adequadamente às orientações da técnica, sugerindo disfunção em seu nível de adequação ao real.

Esses quatro indicadores técnicos da proposta avaliativa de Nijamkin e Braude (1996/2000) para o Questionário Desiderativo, embora simples e de fácil identificação, constituem-se como relevantes sinais para a compreensão do psiquismo humano e, em especial, para avaliar a capacidade do indivíduo de testar sua realidade imediata. Essas informações, por sua vez, tornam-se essenciais em processos de psicodiagnóstico clínico, nos quais a capacidade crítica de exame dos acontecimentos (teste do real) configura-se como elemento central para a identificação de transtornos psicopatológicos.

Conforme informações obtidas a partir da literatura científica, o Desiderativo tem sido usado em uma diversidade de contextos (clínicos ou não) e em pessoas com diferentes características (Capitão \& Zampronha, 2004; Felício, 2002; Paulo, 2005). Os autores referiram, no geral, considerar o Desiderativo um instrumento bastante rico e informativo
(Tardivo, 1999) e, por isso, interessante ao se avaliar o funcionamento da personalidade (Paulo, 2005). Por outro lado, apesar dos indicadores de que o Desiderativo é um instrumento relevante e promissor no que se refere à avaliação do funcionamento psicodinâmico dos indivíduos, ele é, ainda, pouco conhecido em âmbito mais geral em nosso país (Noronha, Primi \& Alchieri, 2005).

Nesse ínterim, verifica-se ainda que, embora haja indicadores da aplicabilidade do Desiderativo em diferentes contextos, é fato que não há, em nossa realidade atual, parâmetros normativos desenvolvidos para essa técnica, numa abordagem psicodinâmica. $\mathrm{O}$ único trabalho dessa natureza que foi captado em buscas nas principais bases de dados que contêm publicações científicas brasileiras foi o de Bunchaft e Vasconcelos (2001), pesquisadoras do Rio de Janeiro, que empreenderam uma tentativa de realizar a padronização dessa técnica com jovens adultos universitários, sendo baseado na abordagem da Análise Transacional e em uma forma de aplicação coletiva do instrumento.

A escassez de estudos psicométricos sobre o Desiderativo constitui-se como um grave limite técnico, quando se considera a situação dos instrumentos de avaliação psicológica no Brasil. Conforme afirma Noronha (2002), apesar de vários autores reafirmarem a importância dos testes psicológicos para o plano de trabalho do profissional, existe uma série de problemas detectados na sua utilização, dentre os quais a pequena quantidade e a má qualidade de dados estatísticos apresentados pelos instrumentos, sobretudo em relação aos testes projetivos.

Especificamente em relação ao Questionário Desiderativo, é sabido que esse instrumento foi avaliado pelo Conselho Federal de Psicologia - CFP (2003), recebendo parecer desfavorável a seu uso por insuficiência de estudos de validade, de precisão e de normas para essa técnica no Brasil, encontrando-se, atualmente, autorizado para utilização dos psicólogos apenas para fins de ensino e de pesquisa. Diante dessa realidade, reforça-se a necessidade de um investimento atual em pesquisas com esse instrumento projetivo, visando alcançar subsídios científicos que possam respaldar sua adequada utilização pelos psicólogos brasileiros. Esse esforço se justifica na medida em que há evidências de que se trata de relevante técnica projetiva, cuja importância tem sido reconhecida pelos profissionais da área da avaliação psicológica (Brêga \& cols., 2001; Capitão \& Zampronha, 2004; Paulo, 2005; Tardivo, 1999).

A necessidade de elaboração de parâmetros avaliativos adequados para análise da produção no Desiderativo fica ainda mais evidente quando se pensa em avaliações com adolescentes, fase de vida na qual a dinâmica psíquica marca-se por vivências agudizadas. Muitas vezes essas vivências acabam inadequadamente compreendidas em seu sentido real, pela falta de adequados parâmetros técnicos de comparação e de análise das produções nas técnicas de avaliação psicológica (Marcelli \& Bracconier, 1999/2007).

Dentro da temática da adolescência, o estudo da personalidade se destaca pela necessidade de se conhecer o seu desenvolvimento e consolidação, processos que sofrem intensas modificações nessa fase da vida (Aberastury, 1978/1983; Osório, 1992). A adolescência, com sua reorganização da vida impulsiva e decorrente aumento de angústias, tende a 
ser um momento favorável para a visualização de reações defensivas tanto internas como comportamentais, permitindo o vislumbre do funcionamento psicodinâmico subjacente a essa fase da vida (Aberastury, 1978/1983).

Segundo Marcelli e Bracconier (1999/2007), mais que em qualquer outra idade da vida, os problemas relacionados à definição do que é normal e do que é patológico se intensificam na adolescência. Os critérios pelos quais se define normalidade e patologia em outras faixas etárias são questionáveis na adolescência, marcando características peculiares dentro do ciclo vital. Considera-se, dessa forma, relevante o investimento em pesquisas nessa área, sobretudo na realidade sócio-cultural contemporânea, buscando conhecer o que é comum (e, portanto, o que poderia ser considerado típico), em relação aos dinamismos psíquicos na adolescência.

Diante das considerações abordadas, pretende-se descrever o padrão geral de respostas de adolescentes (com desenvolvimento típico) diante do Questionário Desiderativo, focalizando as variáveis relacionadas à análise de sua adaptação ao real. Almeja-se, portanto, oferecer novos subsídios técnicos (normas preliminares) para a adequada utilização dessa técnica projetiva na realidade sócio-cultural brasileira contemporânea. Dentre os objetivos específicos, pode-se destacar: apresentar indicadores técnicos do Desiderativo relativos à adequação ao real, objetivando descrever a forma como adolescentes com desenvolvimento típico responderam ao instrumento, permitindo apreciação inicial de seu padrão adaptativo nessa técnica projetiva, e, portanto, na vida. Pretende-se, ainda, destacar as respostas vulgares (mais frequentes) encontradas nesses adolescentes brasileiros.

\section{Método}

\section{Participantes}

Participaram deste estudo 120 adolescentes, de ambos os sexos, de 15 a 18 anos de idade, voluntários, estudantes do Ensino Médio de Ribeirão Preto (SP), com desenvolvimento típico, não apresentando em sua história pessoal transtorno psiquiátrico ou psicológico graves, nem deficiências cognitivas e/ou sensoriais. Esse critério de inclusão na amostra serviu como forma de seleção do considerado "adolescente normal", ou seja, funcionalmente adaptado a seu contexto sócio-cultural.

Essa amostra foi distribuída equitativamente em relação ao sexo e à origem escolar (escola pública ou particular). Obteve-se, assim, dois grupos de adolescentes: 60 do sexo feminino e 60 do sexo masculino, sendo que, em cada um desses grupos, havia 30 provenientes de escolas públicas e 30 de escolas particulares.

\section{Material}

Os adolescentes documentaram sua participação voluntária na pesquisa, assim como seus pais ou responsáveis, assinando Termo de Consentimento Livre e Esclarecido para o estudo (Processo n ${ }^{\circ}$ 199/2005 - 2005.1.928.59.0 do Comitê de Ética em Pesquisa da Faculdade de Filosofia, Ciências e Letras de Ribeirão Preto - Universidade de São Paulo). Foram examinados por meio de entrevista inicial (voltada para a história de desenvolvimento pessoal do participante) e pelo Questionário Desiderativo.

\section{Procedimento}

A coleta de dados dos adolescentes foi realizada individualmente, em local apropriado, nas escolas dos participantes, precedida da autorização por escrito dos diretores da escola e dos pais. As sessões individuais foram iniciadas pela entrevista de histórico de vida (para servir como triagem dos efetivos participantes do estudo) e posterior aplicação do Desiderativo, seguindo-se as recomendações técnicas de Nijamkin e Braude (1996/2000).

\section{Análise de dados}

Após a efetiva coleta de dados, o Questionário Desiderativo foi codificado conforme a proposição avaliativa de Nijamkin e Braude (1996/2000), em sua forma adaptada por Brêga e cols. (2000). Essa análise das respostas foi realizada por três examinadores, de modo independente e às cegas. Esses juízes foram psicólogos com experiência em avaliação psicológica, que passaram previamente por treinamento nessa abordagem específica de avaliação do Desiderativo.

O nível de concordância entre os avaliadores independentes foi examinado, para cada categoria avaliativa, em termos de frequência simples e porcentagem de casos onde ocorreu acordo total (três codificações idênticas entre os avaliadores), acordo parcial (duas codificações idênticas entre os avaliadores) e desacordo (não houve coincidência entre as classificações). A partir do consenso avaliativo obtido entre os examinadores, foi possível a realização da codificação final de cada um dos protocolos do Questionário Desiderativo, material que serviu de base para o presente trabalho.

Buscou-se verificar a existência de eventuais diferenças estatisticamente significativas (adotando-se $p \leq 0,05$ ) entre as respostas fornecidas pelos adolescentes em função do sexo e de sua origem escolar. Assim, procedeu-se ao trabalho de estatística analítica das categorias avaliadas, recorrendo-se ao teste de Mann-Whitney para comparar as distribuições nas variáveis numéricas (no caso, TRM e número de respostas), e ao teste Qui-quadrado ou Exato de Fisher para comparar as distribuições nas variáveis categóricas nominais (sequência das escolhas, razões das induções e respostas antropomórficas).

Os resultados foram apresentados em forma de estatística descritiva (média, desvio padrão, mínimo e máximo, percentis 25,50 e 75, para as variáveis numéricas) e frequência simples e porcentagem para as variáveis categóricas nominais em questão.

Realizou-se, ainda, classificação da frequência das escolhas e rejeições, verificando-se as respostas mais frequentes (vulgares), conforme realizado por Bunchaft e Vasconcelos (2001). Para tanto, utilizou-se o critério adotado por essas autoras, a saber: as escolhas (positivas ou negativas) realizadas por pelo menos $14 \%$ dos participantes foram consideradas vulgares. 


\section{Resultados e Discussão}

Cumpre reiterar que os resultados apresentados nesse momento focalizam as informações provenientes da avaliação dos indicadores do Questionário Desiderativo referentes à Adequação ao Real, conforme proposição avaliativa de Nijamkin e Braude (1996/2000), adaptada por Brêga e cols. (2000). Assim, serão destacados os resultados referentes ao TRM, Sequência das Escolhas, Necessidade de Indução e Respostas Antropomórficas, além do destaque para as respostas mais frequentes (vulgares). Os resultados referentes aos demais indicadores do Questionário Desiderativo, conforme a proposição avaliativa adotada, podem ser encontrados em Guimarães (2007).

A classificação das respostas ao Desiderativo, realizada por examinadores independentes, buscou garantir precisão avaliativa às análises realizadas. Considerando-se as diversas categorias de classificação desse material projetivo, o procedimento adotado para análise dessa precisão considerou a frequência de distribuição de acordos (parcial ou total) e de desacordos entre os avaliadores no conjunto dos 120 casos presentemente avaliados. Esses resultados encontram-se na Tabela 1.

A partir dos dados apresentados na Tabela 1 foi possível verificar a existência de acordo (parcial ou total) em todas as categorias avaliativas referentes à Adequação ao Real. $\mathrm{Na}$ maioria delas foi frequente o acordo total, ou seja, três codificações idênticas entre avaliadores para as categorias utilizadas na classificação das respostas ao Desiderativo. Não houve desacordo entre examinadores em nenhuma dessas categorias de análise.

Esses dados evidenciaram precisão nas análises realizadas nas categorias avaliativas referentes à Adequação ao Real, segundo o sistema avaliativo proposto por Nijamkin e Braude (1996/2000) e adaptado por Brêga e cols. (2000). A presença de acordos totais entre examinadores foi alta $(95,8 \%)$, o que se configurou como relevante evidência empírica que, para além de fundamentar tecnicamente o sistema avaliativo utilizado para essa técnica projetiva, sustenta a confiabilidade do conjunto de resultados obtidos por meio dessas análises.

Retornando à descrição e à análise da possível influência do sexo e da origem escolar dos adolescentes no Questionário Desiderativo, verificou-se que não houve diferenças significativas de desempenho entre eles. Assim, conforme detalhamento a seguir, para esse grupo de adolescentes examinados, nem a origem escolar nem o sexo se mostraram variáveis relevantes em relação à sua forma de responder ao Desiderativo, no que se refere aos indicadores avaliativos da Adequação ao Real (TRM, Sequência das Escolhas, Necessidade de Indução e Respostas Antropomórficas). Assim, fundamentou-se a apresentação dos resultados referente ao grupo geral $(\mathrm{n}=120)$, sem análise específica por sexo ou por origem escolar dos adolescentes.

\section{Tempo de reação médio (TRM)}

Para descrever o padrão médio de reatividade temporal dos adolescentes diante das questões do Desiderativo, elaborou-se a Tabela 2. Conforme relatado anteriormente, não foram verificadas diferenças estatisticamente significativas no TRM dos adolescentes, nem com referência ao sexo (Teste Mann-Whitney, $p=0,577)$, nem com relação à origem escolar (Teste Mann-Whitney, $p=0,324$ ).

Como foi possível verificar, os valores médios de TRM encontrados na presente investigação respeitam o padrão de normalidade proposto por Ocampo e cols. (1979/1985) (entre 5 e 30 segundos). Verificou-se também que os valores de TRM foram maiores nas catexes negativas que nas positivas. Assim, os adolescentes avaliados tenderam a demorar mais para responder às catexes negativas, o que pode significar, entre outros aspectos, maior nível de ansiedade ao serem solicitados a reconhecer conteúdos desintegradores de seu mundo interno.

Além disso, esses adolescentes evidenciaram maior rapidez para identificar, projetivamente, seus recursos de preservação da identidade (respostas às catexes positivas), reagindo com necessidade de tempo maior para apontar elementos sentidos como desintegradores (respostas às catexes negativas). Nijamkin e Braude (1996/2000), em relação a este aspecto, comentam que tanto um aumento quanto uma diminuição relevante no tempo de reação constituem sinais de que existe situação de conflito para o indivíduo. Dessa maneira, o aumento do TRM nas catexes negativas, conforme encontrado na presente investigação, pode ser indicador de maior mobilização afetiva ao responder a estas consignas.

Tabela 1. Distribuição (em frequência simples e porcentagem), do índice de acordo entre examinadores nas categorias avaliativas referentes à Adequação ao Real, pelo Desiderativo, referente aos adolescentes avaliados ( $\mathrm{n}=120)$.

\begin{tabular}{|c|c|c|c|c|c|c|}
\hline \multicolumn{7}{|c|}{ Análise dos Examinadores } \\
\hline \multirow{3}{*}{ Categoria Avaliativa } & \multicolumn{4}{|c|}{ Acordo } & \multirow{2}{*}{\multicolumn{2}{|c|}{ Desacordo }} \\
\hline & \multicolumn{2}{|c|}{ Total } & \multicolumn{2}{|c|}{ Parcial } & & \\
\hline & $\mathrm{f}$ & $\%$ & $\mathrm{f}$ & $\%$ & $\mathrm{f}$ & $\%$ \\
\hline Tempo de reação médio (TRM) & 119 & 99,2 & 1 & 0,8 & - & - \\
\hline Sequência das escolhas & 115 & 95,8 & 5 & 4,2 & - & - \\
\hline Necessidade de indução & 114 & 95,0 & 6 & 5,0 & - & - \\
\hline Respostas Antropomórficas & 112 & 93,3 & 8 & 6,7 & - & - \\
\hline Média & 115 & 95,8 & 5 & 4,2 & - & - \\
\hline Desvio Padrão & 2,9 & 2,5 & 2,9 & 2,5 & - & - \\
\hline
\end{tabular}


Tabela 2. Descrição do Tempo de Reação Médio (TRM) (em segundos) dos adolescentes $(\mathrm{n}=120)$ nas catexes positivas e negativas do Questionário Desiderativo.

\begin{tabular}{|c|c|c|c|c|c|c|c|}
\hline \multirow{3}{*}{ Catexes } & \multicolumn{7}{|c|}{ Tempo de Reação Médio } \\
\hline & \multirow{2}{*}{ Média } & \multirow{2}{*}{ D. P. } & \multirow{2}{*}{ Mínimo } & \multirow{2}{*}{ Máximo } & \multicolumn{3}{|c|}{ Percentis } \\
\hline & & & & & 25 & 50 & 75 \\
\hline Positivas & 13,6 & 10,3 & 2,0 & 63,0 & 6,2 & 10,0 & 19,0 \\
\hline Negativas & 18,4 & 15,8 & 1,0 & 102,0 & 8,0 & 14,0 & 22,8 \\
\hline
\end{tabular}

\section{Sequência das escolhas}

Dentro dessa categoria avaliativa, há que se considerar dois diferentes componentes: quantidade de respostas produzidas e sequenciação das escolhas, em função do nível de preservação de vida implícito em cada uma das respostas.

Os adolescentes produziram semelhante número de respostas diante das catexes positivas e negativas, ficando entre três ou quatro, na maioria dos casos. Ressalta-se que não houve diferenças significativas em relação ao sexo, nem à origem escolar, no que se refere ao número de respostas positivas e negativas ao Desiderativo (Teste Mann-Whitney, $p=0,136$ ). Houve grande proporção de adolescentes que emitiram três respostas às duas partes do Desiderativo (45\% da amostra no caso das catexes positivas e $27,5 \%$ da amostra nas negativas), o que corresponderia ao esperado para a técnica, sugerindo flexibilidade egóica e adequado nível de adaptação geral à realidade (Nijamkin \& Braude, 1996/2000; Ocampo \& cols., 1979/1985).

Apesar dessa evidência anterior, foi possível verificar que o número de respostas mais frequente a cada parte do Desiderativo foi quatro ( $48,3 \%$ dos participantes nas catexes positivas e $57,5 \%$ deles nas negativas). Assim, percebeu-se que foi fato comum, entre os adolescentes presentemente avaliados (considerados saudáveis), cometer uma falha ao responder ao Desiderativo. Destaca-se, em virtude dessa informação, a necessidade de relativizar o caráter patológico tradicionalmente atribuído à ocorrência de uma falha ao responder, no protocolo do Questionário Desiderativo (Nijamkin e Braude, 1996/2000; Ocampo \& cols., 1979/1985), ao menos quando se trata do período da adolescência.

Cabe, por fim, apontar que alguns adolescentes produziram duas ou mais falhas ao responder ao Desiderativo, resultando em mais de quatro respostas às duas partes dessa técnica projetiva. Esses casos, na verdade, constituíram-se em exceções dentro da amostra presentemente estudada. $\mathrm{Ou}$ seja, a maioria dos adolescentes não necessitou da quinta ou da sexta resposta para completar a tarefa.

Examinando-se os dados da Tabela 3, pode-se notar que na primeira resposta dos adolescentes diante das catexes positivas e negativas do Desiderativo, a resposta animal foi a mais frequente. Isto está de acordo com o previsto pela técnica, sugerindo predomínio dos impulsos de conservação e de vida sobre os impulsos de morte (Nijamkin \& Braude, 1996/2000; Ocampo \& cols., 1979/1985). Nas catexes negativas houve, além disso, um aumento relacionado às respostas objeto, sendo que essas foram a segunda classe de escolhas mais frequente diante dessa segunda parte do Questionário Desiderativo. Parece, portanto, que também foi bastante rejeitada pelos adolescentes a desvitalização implícita nas respostas do tipo inanimado (objeto).

Em relação a esse aspecto, Nijamkin e Braude (1996/2000) comentaram que, nas catexes negativas, a escolha daquilo que o examinando primeiramente rejeita depende do que é sentido e experienciado como conflitivo, podendo vincularse aos próprios impulsos rejeitados ou à angústia ligada à desvitalização e à morte, própria das respostas de caráter inanimado. Dentro dessas possibilidades interpretativas, pode-se depreender que os adolescentes presentemente avaliados sinalizaram desejos de preservar a vitalidade ao escolherem prioritariamente animais como primeira escolha positiva, reafirmando força em seu dinamismo psíquico. Ao mesmo tempo, contudo, sinalizaram também temor e rejeição dessa mesma força, advinda dos impulsos, pois também diante das catexes negativas a escolha prioritária foi a do reino animal.

Em ambas as catexes, o reino objeto foi o mais frequente como segunda resposta, diferindo do teoricamente esperado (Ocampo \& cols., 1979/1985), já que objeto corresponde a uma categoria mais desvitalizada do que o reino vegetal. Houve também maior frequência de perseveração do reino objeto nas catexes negativas. Esse resultado reforça ainda mais a importância simbólica das respostas dessa classe inanimada (objeto) como segunda categoria de respostas às catexes negativas do Desiderativo, no grupo de adolescentes avaliados.

Analisando-se a continuidade da sequência das escolhas desiderativas (terceira, quarta, quinta e sexta respostas), o resultado foi bastante semelhante nas catexes positivas e negativas. Como terceira classe de escolhas, o predomínio de respostas do tipo objeto foi acompanhado também por perseveração nesse reino e por redução da frequência nas respostas animal e vegetal.

Em relação à quarta resposta, fica clara a rejeição pela classe vegetal nos adolescentes, talvez sinalizando seu temor de imobilização e enraizamento. Nota-se que quase metade deles escolheu, como quarta opção das consignas negativas, uma resposta do tipo vegetal, tendo essa categoria de respostas ocorrido menos frequentemente nas primeiras respostas positivas. Jardim-Maran (2004) e Tardivo (1999) encontraram resultados semelhantes aos da presente investigação, tendo as respostas do reino vegetal aparecido menos frequentemente que as do reino objeto, nas escolhas positivas iniciais.

Foi possível verificar, por fim, um aumento das recusas, nas catexes negativas, em relação às positivas. Além disso, percebe-se que nas catexes positivas houve maior índice de respostas antropomórficas que nas catexes negativas. 
Tabela 3. Distribuição (em porcentagem) dos adolescentes ( $n=120)$ em função do tipo e da sequência de escolhas nas catexes positivas e negativas do Questionário Desiderativo.

\begin{tabular}{|c|c|c|c|c|c|c|c|c|}
\hline \multirow{2}{*}{\multicolumn{2}{|c|}{ Tipo de Resposta }} & \multirow{2}{*}{ Catexes } & \multicolumn{6}{|c|}{ Sequência das Escolhas } \\
\hline & & & $1^{\mathrm{a}}$ & $2^{\mathrm{a}}$ & $3^{\mathrm{a}}$ & $4^{\mathrm{a}}$ & $5^{\mathrm{a}}$ & $6^{\mathrm{a}}$ \\
\hline \multirow{2}{*}{\multicolumn{2}{|c|}{ Recusa }} & Pos & 0,8 & - & 3,3 & 0,8 & 0,8 & - \\
\hline & & Neg & 0,8 & 6,7 & 6,7 & 3,3 & 1,7 & - \\
\hline \multirow{2}{*}{\multicolumn{2}{|c|}{ Animal }} & Pos & 79,2 & 15,8 & 4,2 & 0,8 & - & - \\
\hline & & Neg & 55,8 & 20,8 & 8,3 & 6,7 & 7,5 & 0,8 \\
\hline \multirow{2}{*}{\multicolumn{2}{|c|}{ Vegetal }} & Pos & 4,2 & 25,0 & 30,0 & 33,3 & 5,0 & - \\
\hline & & Neg & 5,0 & 14,2 & 33,3 & 44,2 & 3,3 & - \\
\hline \multirow{2}{*}{\multicolumn{2}{|c|}{ Objeto }} & Pos & 10,0 & 46,7 & 30,0 & 11,7 & - & 1,7 \\
\hline & & Neg & 35,8 & 45,0 & 9,2 & 4,2 & 2,5 & - \\
\hline \multirow{2}{*}{\multicolumn{2}{|c|}{ Antropomórfica }} & Pos & 5,8 & 6,7 & 4,2 & 0,8 & 0,8 & - \\
\hline & & Neg & 2,5 & 1,7 & 2,5 & - & - & - \\
\hline \multirow{6}{*}{ Perseve-ração } & \multirow{2}{*}{ Animal } & Pos & - & 4,2 & 1,7 & - & - & - \\
\hline & & Neg & - & 0,8 & 3,3 & 1,7 & - & - \\
\hline & \multirow{2}{*}{ Vegetal } & Pos & - & - & - & - & - & - \\
\hline & & Neg & - & - & - & - & - & - \\
\hline & \multirow{2}{*}{ Objeto } & Pos & - & 1,7 & 26,7 & 5,8 & 1,7 & - \\
\hline & & $\mathrm{Neg}$ & - & 10,8 & 36,7 & 10,0 & 0,8 & - \\
\hline \multirow{2}{*}{\multicolumn{2}{|c|}{ Inexistente }} & Pos & - & - & - & 46,7 & 91,7 & 98,3 \\
\hline & & Neg & - & - & - & 30,0 & 84,2 & 99,2 \\
\hline
\end{tabular}

Nota: Pos = catexes positivas; Neg = catexes negativas.

Assim, a tendência a preservar a vitalidade, associada a dificuldades em separar-se da identidade humana, estiveram presentes com força relevante nas catexes positivas. Ao mesmo tempo, houve sinais de maior mobilização afetiva frente às catexes negativas, associadas a um aumento da ansiedade, e a ocorrência de bloqueios associativos mais frequentes que nas catexes positivas.

\section{Necessidade de indução}

No Questionário Desiderativo, ocorre a necessidade de indução, por parte do examinador, quando o respondente realiza uma falha ao responder. Faz-se necessário avaliar, nessa proposição avaliativa, em que medida induções foram necessárias nos adolescentes avaliados, bem como as razões pelas quais elas ocorreram nas catexes positivas e negativas.

Novamente, conforme já destacado, não foram encontradas diferenças estatisticamente significativas na frequência com que os adolescentes necessitaram de indução para completar o Desiderativo, nem em função do sexo (Teste Quiquadrado, $p=0,6323)$, tampouco em função de sua origem escolar (Teste Qui-quadrado, $p=0,7865$ ).

Nos adolescentes presentemente avaliados, foi possível perceber, em primeiro lugar, que o número de induções foi maior nas catexes negativas (ocorreu em 70,8\% dos adolescentes) que nas positivas (em $54,2 \%$ deles). Isso pode significar que, de alguma forma, foi mais fácil para os ado- lescentes seguirem corretamente as instruções nas catexes positivas que nas negativas. Em outras palavras, pode-se interpretar que eles conseguiram identificar suficientemente os elementos internos de preservação de sua identidade (catexes positivas), enfrentando alguns bloqueios diante da busca pelos aspectos desintegradores internos (catexes negativas), frente aos quais precisaram do auxílio externo (indução de categorias de respostas).

Além disso, o reino vegetal foi o respondido de forma menos espontânea pelos adolescentes, visto que foi, de longe, o mais induzido no conjunto de adolescentes examinados (em $42,5 \%$ dos adolescentes, nas positivas e em 48,3\% deles, nas negativas). Esse fato pode estar relacionado a uma rejeição projetiva de aspectos relativos à estagnação e à imobilidade, geralmente atribuídos aos elementos do reino vegetal pelos adolescentes examinados, conforme já sinalizado anteriormente.

Com relação aos motivos que levaram à necessidade de induzir respostas nesses adolescentes, foi possível verificar que o fator pregnante na determinação dos processos de indução de respostas no Desiderativo foi a perseveração de reino (em $31,3 \%$ dos participantes, nas catexes positivas e em $43,3 \%$ deles, nas negativas), sendo maior a frequência de ocorrência dessa falha nas catexes negativas. Aumento semelhante foi possível perceber em relação às recusas, que ocorreram em 9,2\% dos adolescentes nas catexes negativas e em apenas 2,5\% deles, nas positivas. Esse conjunto de informações reforça a hipótese anterior de maiores dificuldades para os adolescentes ao responder às consignas negativas. 
Em uma pequena parcela dos adolescentes $(5,8 \%$ nas catexes positivas e $15,0 \%$ nas negativas) foi necessário realizar a indução de mais de um reino. Isso se relaciona ao fato, depreendido também pela análise da Tabela 3 , de que poucos adolescentes realizaram mais de uma falha ao responder ao Desiderativo, necessitando de mais de quatro respostas para completar a tarefa proposta.

Buscando detalhar ainda mais a análise das respostas desses adolescentes, sobretudo, relativamente a seus bloqueios de categorias de resposta, procurou-se examinar as frequências das respostas perseverativas, descrevendo o reino nelas implícito. Nessa direção, verificou-se que o reino objeto foi o mais frequentemente perseverado pelos adolescentes, tendo ocorrido em $32,5 \%$ deles nas catexes positivas e em $50,0 \%$ deles, nas negativas. As perseverações do reino animal foram bem menos frequentes, tendo ocorrido em apenas $5,8 \%$ dos adolescentes nas catexes positivas e em 5,0\% deles, nas negativas. Essas informações se relacionam à menor necessidade de indução desses reinos durante as avaliações. Por outro lado, o reino vegetal não foi repetido nas respostas ao Desiderativo por nenhum dos adolescentes, o que acabou se relacionando com maior necessidade de indução desse reino, claramente menos escolhido por todos.

É relevante notar que nas catexes negativas houve maior frequência de perseveração do reino objeto que nas positivas, o que pode ser considerado teoricamente esperado. Isso porque, ao apontar os elementos causadores de angústia de seu mundo interno, os participantes preferiram (projetivamente) rejeitar com mais frequência as respostas do reino objeto, ou seja, elementos desvitalizados. Quando se considera que o esperado teoricamente para indivíduos saudáveis é a preservação da vitalidade (Ocampo \& cols., 1979/1985), é possível considerar a rejeição de elementos desvitalizados algo compatível com um modo de funcionamento mais adaptativo.

Contudo, há que se pensar em uma possível limitação técnica do instrumento que poderia tender a estimular a perseveração do reino objeto. Dentro da proposição avaliativa adotada, o reino "objeto" abarca uma variedade de conteúdos, como fenômenos da natureza, sentimentos, doenças, entre outros, que poderiam merecer classificação diferente dessa categoria "objeto". Isso poderia ter levado os adolescentes a emitirem respostas que, embora classificadas como pertencentes ao reino objeto, não configurassem objetos propriamente ditos, ocorrendo muitas vezes que, quando instruídos a não utilizarem esse reino, ainda o escolhessem por compreenderem a classe de objetos como algo diferente da classificação utilizada na técnica (elemento inanimado). Essa falha em seguir a orientação oferecida é interpretada como perseveração de reino, na proposição avaliativa de Nijamkin e Braude (1996/2000), embora com as ressalvas presentemente consideradas.

Comentários pertinentes a essas dificuldades técnicas do Desiderativo foram elaborados também por Bunchaft e Vasconcelos (2001). Essas autoras ponderaram ser relevante transformar a categoria "objeto" em uma classe abrangente e que pudesse incluir tanto seres inanimados como abstrações e elementos da natureza. Sugeriram ainda aumento no número de perguntas, de modo a discriminar entre ser inanimado, força natural/fenômeno da natureza e abstração. É possível que, em aplicações do Desiderativo transformadas dessa maneira, apareçam resultados diferentes dos encontrados na presente avaliação. Porém, essa hipótese exigiria explanações que extrapolariam os objetivos da presente investigação.

\section{Respostas antropomórficas}

A presença ou não de respostas antropomórficas nos protocolos do Desiderativo é um elemento bastante importante na avaliação da personalidade dos indivíduos, estando relacionada à forma pela qual os adolescentes se adaptaram às instruções do teste.

Nesse item avaliativo do Desiderativo, a baixa frequência de respostas antropomórficas não permitiu a realização de testes estatísticos esclarecedores de possível influência do sexo e da origem escolar sobre os resultados. Dessa forma, a análise dessa variável nesse trabalho segue um delineamento descritivo.

Foi possível verificar que a frequência de respostas antropomórficas foi baixa tanto nas catexes positivas (em 15\% dos adolescentes) quanto nas negativas (em 6,7\% deles). Assim, a maioria dos adolescentes conseguiu responder ao Desiderativo sem maiores dificuldades em desvencilhar-se da identidade humana, ou seja, com adequada adaptação às instruções da técnica.

Cumpre salientar que nas catexes negativas os índices de respostas antropomórficas foram menores que nas positivas. Pode-se tentar compreender essa evidência como relacionada, entre outros aspectos, a uma maior carga de idealização presente quando os adolescentes precisavam destacar, projetivamente, os aspectos bons de sua identidade, aqueles que mais gostariam de preservar, atendo-se, nesses casos, a escolhas mais diretamente associadas a elementos antropomórficos. Alguns exemplos de respostas antropomórficas referidas pelos adolescentes presentemente avaliados foram: "anjo", "espírito", "sereia", nas catexes positivas, e "assassino", "demônio", "pessoa má", nas catexes negativas.

\section{Respostas vulgares}

Além das informações já apresentadas, faz-se necessário conhecer quais as respostas escolhidas positivamente, bem como os elementos mais frequentemente rejeitados pelos adolescentes avaliados. Buscou-se organizar esses resultados em função dos reinos das respectivas respostas (animal, vegetal e objeto), separando-se as respostas positivamente escolhidas daquelas negativamente referidas pelo conjunto dos adolescentes.

Houve uma grande variabilidade na emissão de respostas pelos adolescentes avaliados. Essa variabilidade se deu, sobretudo, nas catexes negativas. Dessa forma, houve poucas respostas produzidas com frequência suficiente para serem consideradas vulgares (frequência mínima de 14\% no grupo avaliado, conforme Bunchaft \& Vasconcelos, 2001). Foi necessário estabelecer alguns agrupamentos dessas respostas, com o objetivo de vislumbrar escolhas mais frequentes entre os adolescentes avaliados. Para a presente análise, todas as respostas foram contabilizadas, 
incluindo-se aquelas emitidas em perseverações de reino. As demais respostas, que não constam da Tabela 4, ocorreram em frequência tão baixa que nem mesmo em agrupamentos puderam ser consideradas para a análise de seu caráter banal ou não no grupo como um todo, sendo desprezadas nessa classificação.

Como foi possível perceber na análise das respostas vulgares, animais como "pássaro" ou "aves" estiveram maciçamente presentes no rol de escolhas pelos participantes, totalizando cerca de metade das escolhas animais desses adolescentes, tendo sido, na maioria das vezes, associados à ideia de liberdade. Nas respostas negativas, foram os "insetos" e os "quadrúpedes domésticos" que se sobressaíram em frequência dentre as rejeições dos participantes, na maioria das vezes sendo percebidos como potencialmente causadores de prejuízos às pessoas.

No reino vegetal, as "flores" se sobressaíram dentre as escolhas vegetais, com destaque para a resposta "rosa", que, dentre todas as flores escolhidas, foi a única que alcançou, sozinha, frequência suficiente para ser considerada resposta vulgar. Interessante perceber que a categoria de respostas "flores" foi frequentemente mencionada pelos adolescentes também nas respostas negativas, sinalizando, assim, serem elementos percebidos de modo ambivalente pelos participantes.
No reino objeto, a variabilidade de respostas foi maior, não havendo nenhuma resposta que tenha alcançado (sozinha) o caráter de banalidade na amostra presentemente estudada. Como categoria de resposta, destacaram-se os elementos e fenômenos da natureza, que foram frequentes tanto no grupo de objetos escolhidos como nos rejeitados pelos adolescentes participantes, tanto pela magnitude e beleza dos mesmos, como em virtude de sua força e potencial destrutividade.

\section{Considerações Finais}

A partir desse percurso investigativo, foram obtidos resultados favorecedores da utilização do Questionário Desiderativo no contexto brasileiro contemporâneo, com base na proposição avaliativa de Nijamkin e Braude (1996/2000), conforme adaptação realizada por Brêga e cols. (2000). Podese encontrar evidências empíricas que sustentam a possibilidade de alcance de indicadores da dinâmica psíquica interna dos adolescentes, em seu processo de adaptação à realidade imediata, por meio dessa técnica projetiva.

Os indicadores referentes à precisão das análises realizadas favorecem a adoção da referida proposição avaliativa. No entanto, faz-se necessário destacar que, para que seja alcan-

Tabela 4. Distribuição (em porcentagem) das respostas (ou grupos de respostas) consideradas vulgares, em função de sua frequência de ocorrência entre os adolescentes examinados $(\mathrm{n}=120)$.

\begin{tabular}{|c|c|c|c|}
\hline Catexes & Reinos & Grupos de respostas & $\%$ \\
\hline \multirow{7}{*}{ Positivas } & \multirow{3}{*}{ Animal } & Pássaro & 26,8 \\
\hline & & Aves (águia, ave, beija-flor, falcão, gaivota, gavião, papagaio e pombo) & 23,7 \\
\hline & & Cães (cachorro, cachorrinho e poodle) & 15,0 \\
\hline & \multirow{3}{*}{ Vegetal } & Árvore & 26,7 \\
\hline & & $\begin{array}{l}\text { Flores (bromélia, camarão, copo-de-leite, cravo, flor, flor do campo, girassol, lírio, orquídea, } \\
\text { violeta e vitória-régia) }\end{array}$ & 26,5 \\
\hline & & Rosa & 21,7 \\
\hline & Objeto & $\begin{array}{l}\text { Elem./fen. da natureza (água, ar, arco-íris, concha, estrela, grão de areia, lua, mar, nuvem, } \\
\text { oceano, pedra, rio, sol, terra, vento). } \\
\text { Móveis/utensílios domésticos (armário, cama, computador, crucifixo, espelho, estátua, faca, } \\
\text { lâmpada, mesa, parede, quadro, rádio, relógio, telefone, televisão). }\end{array}$ & 40,7 \\
\hline \multirow{6}{*}{ Negativas } & \multirow{2}{*}{ Animal } & Insetos (barata, borboleta, escorpião, formiga, inseto, marimbondo, mosca, varejeira, vespa) & 23,7 \\
\hline & & Quadrúpedes domésticos (boi, burro, cachorro, cavalo, chinchila, gato, vaca) & 27,7 \\
\hline & \multirow[t]{3}{*}{ Vegetal } & $\begin{array}{l}\text { Plantas de pequeno porte (arbusto, arruda, boldo, cama de noiva, cana de açúcar, canabis, } \\
\text { carnívora, comigo-ninguém-pode, coroa de cristo, erva daninha, erva parasita, folhagem, } \\
\text { maconha, samambaia, trepadeira) }\end{array}$ & 25,4 \\
\hline & & Flores (cravo, flor, flor de jardim, flor do campo, girassol, margarida, rosa, violeta) & 22,4 \\
\hline & & Grama/capim & 15,0 \\
\hline & Objeto & $\begin{array}{l}\text { Elem/fen da natureza (água, água do mar, ar, ar de cidade, caverna, chuva, córrego, estrela, } \\
\text { fogo, fumaça, inverno, lua, madeira, nuvem, planeta, pólo norte, poluição, rio, rio poluído, sol, } \\
\text { Terra, terremoto, universo, vento, vulcão) }\end{array}$ & 24,7 \\
\hline
\end{tabular}


çada essa precisão analítica, torna-se essencial um adequado treinamento dos avaliadores em relação a essa abordagem. Esses resultados atentam para a necessidade de investimentos na formação dos psicólogos na área da avaliação psicológica, como forma de garantir a qualidade dos processos psicodiagnósticos realizados em conformidade com os apontamentos de Noronha (2002), entre tantos outros trabalhos.

Além disso, considera-se que as informações trazidas por este trabalho, referentes aos aspectos formais do desempenho dos adolescentes diante do Questionário Desiderativo, fornecem subsídios científicos iniciais favorecedores à utilização desse instrumento projetivo em avaliações psicológicas. Considera-se que essas informações são relevantes por possibilitarem a identificação daquilo que é comum, entre adolescentes com desenvolvimento típico, ao responder ao Questionário Desiderativo.

Ressalta-se, ainda, a necessidade de mais investimentos em pesquisas voltadas para a investigação da validade do Questionário Desiderativo como técnica de avaliação de personalidade no contexto sócio-cultural brasileiro. Além disso, estudos voltados para elaboração de normas para outros grupos e/ou faixas etárias tornam-se necessários, com o objetivo de torná-lo um instrumento acessível à utilização (cientificamente fundamentada), por psicólogos de nosso país.

\section{Referências}

Aberastury, A. (1983). Adolescência (R. Cabral, Trad.) Porto Alegre: Artes Médicas (Trabalho original publicado em 1978).

Brêga, F. M. P., Frazatto, L., \& Loureiro, S. R (2000). Questionário Desiderativo - Fundamentação, codificação e análise [trabalho não publicado]. Departamento de Neurologia, Psiquiatria e Psicologia Médica da FMRP-USP.

Brêga, F. M. P., Frazatto, L., \& Loureiro, S. R. (2001). Pacientes com características paranóides: funcionamento defensivo. Psico USF, 6, 85-94.

Bunchaft, G., \& Vasconcellos, V. L. P. (2001). Padronização do Teste Desiderativo no contexto da Análise Transacional: resultados preliminares. Psicologia: Teoria e Pesquisa; 17, 19-25.

Capitão, C. G., \& Zampronha, M. A. G. (2004). Câncer na adolescência: um estudo com instrumento projetivo [versão eletrônica]. Revista da SBPH, 7, 3-16.

Conselho Federal de Psicologia - CFP (2003). Resolução 002/03. Define e regulamenta o uso, a elaboração e a comercialização de testes psicológicos. Retirado em 15/05/2007, de http://www.pol.org.br.
Felício, J. L. (2002). Sobre a personalidade de homens com disfunção erétil ou ejaculação precoce: estudo comparativo como Inventário Fatorial de Personalidade, o Questionário Desiderativo e o Teste Estilocrômico. Tese de Doutorado, Universidade de São Paulo, São Paulo.

Guimarães, N. M. (2007). O dinamismo psíquico na adolescência: indicadores normativos do Questionário Desiderativo. Dissertação de Mestrado, Universidade de São Paulo, Ribeirão Preto.

Jardim-Maran, M. L. C. (2004). A escolha profissional de adolescentes através do BBT-Br e do Questionário Desiderativo. Dissertação de Mestrado, Universidade de São Paulo, Ribeirão Preto.

Marcelli, D., \& Braconnier, A. (2007). Adolescência e psicopatologia (F. Murad, Trad.). Porto Alegre: Artmed (Trabalho original publicado em 1999).

Nijamkin, G. C., \& Braude, M. G. (2000). O Questionário Desiderativo (L. S. L. P. C. Tardivo, trad.). São Paulo: Vetor (Trabalho original publicado em 1996).

Noronha, A. P. P. (2002). Os problemas mais graves e mais frequentes no uso dos testes psicológicos. Psicologia: Reflexão e Crítica, 15, 135-142.

Noronha, A. P. P., Primi, R., \& Alchieri, J. C. (2005). Instrumentos de avaliação mais conhecidos/estudados por psicólogos e estudantes de Psicologia. Psicologia: Reflexão e Crítica, 18, 390-401.

Ocampo, M. L. S., Arzeno, M. E. G., \& Piccolo, E. G. (1985). O Processo diagnóstico e as técnicas projetivas (M. Felzenszwalb, Trad.). São Paulo: Martins Fontes (Trabalho original publicado em 1979).

Osório, L.C. (1992). Adolescente hoje. Porto Alegre: Artes Médicas

Paulo, M. S. L. L. (2005). Psicodiagnóstico e intervenção terapêutica de pacientes adultos com depressão [Resumo]. Em Instituto Brasileiro de Avaliação Psicológica (Org.), Resumos do II Congresso Brasileiro de Avaliação Psicológica - Desafios para a formação, prática e pesquisa (pp. 2-3). Porto Alegre: Instituto Brasileiro de Avaliação Psicológica.

Tardivo, L. S. L. P. C. (1999). A estruturação do ego: o estudo do grau de estruturação do ego de profissionais de saúde através do Questionário Desiderativo. Revista da Vetor Editora, 1, 28-34. 